\title{
Discussion on the Function and Significance of Website for Music
}

\author{
Education
}

\author{
Yuan Li \\ College of Music ,Jiangxi University of Technology
}

Keywords: Education carrier; Music education website; Network communication.

\begin{abstract}
With the rapid development of modern science and technology, achievements of high technology have also been applied to educational field. Since the beginning of 21 st century, informatized network education, a new model symbolized with Internet, has greatly influenced educational methods, contents and concepts so that education has been developed deeply and vertically. As for contemporary music education, it has also employed network technology, this new education carrier inevitably. In this paper, music education website is taken as the main research subject. It explores the important effect of music education website on improving music education development as a whole new education carrier. Besides, it gives a concrete analysis on the contents style, layout of educational resources as well as network technology of music education website. By comparing music education home and abroad, the author hopes to present the huge advantages of music education website in realizing resource sharing and a diversified culture as a whole new carrier. Meanwhile, there are also some problems that music education websites need to solve. These problems will also be discussed in this paper with proposal of some countermeasures.
\end{abstract}

\section{Introduction}

In the 21 st century, ways of people's life and production have been deeply impacted with the development of various scientific technologies. Since the 1990s, information technology revolution based on multi-media technology and Internet has been developed rapidly, and meanwhile ways of people's life and work have also been changed greatly. The concepts of "global village" and "global integration" have been deep inside people's mind. Network information technology has become an important part of human's life since people are acquiring more and more information from Internet with an extensive range.

As a carrier of education, network information technology plays an important role in the development of human's civilization. When we look back into the history, we find that characters and printing, as education carriers, were once widely spread across States for a long time as huge bridges for human's communication, which played an epochal-making role in the development and progress of human's civilization.

Meanwhile, it also has important role and significance for the change of human's teaching mode and teaching thoughts. In fact, carrier is especially important for education. For example, books, documents and dictionaries which take paper as a carrier are the most basic carriers for education, so innovation of education carrier is a major breakthrough. Nowadays network has been developed into a new education carrier, which has provided many possibilities for music education. Many music educationists are working hard to make better use of this new education carrier to develop music 
education so as to make up for defects of traditional educational modes. Advanced technology has been applied to music education consecutively by music education websites home and abroad, covering various aspects of music education such as classification and concepts, which will have a positive effect on the whole field.

From the perspective of comparative education, music education website supported by contemporary network technology is of especially important significance for global resources sharing. Besides, music education website is also an important platform for the study of music education, which has become a new resource of contemporary comparative research. The results gained from the research will provide us with new concepts and methods for reviewing music education. In the paper, with introduction to the new carrier of music education under global integration, it elaborates the significance and effect of the carrier on music education. Next, more emphasis will be laid on an comparative study of music education websites, which can fully embody the ideological ways of music education, from various perspectives by taking famous professional conservators of music as well as official and folk music education websites home and abroad as examples. Specific research will be conducted on the classification, service objects as well as contents and ideological ways of some influential music education websites home and abroad.

In the paper, literature review, analysis of written materials and comparative analysis will be employed to conduct a complete and powerful study as well as possible.

\section{The effect of an innovative information technology carrier on education}

The effect on teaching mode. In the traditional teaching mode, which is based on teacher and teaching materials, teacher whose main responsibility is teaching students knowledge and skills is in a dominant position with an active role; while students are in a passive role to some extent. However, during the process of informatization education, the roles of students and teacher have been changed. Under this new mode, students are seen as the main body, while teacher is just a leader who helps students to reach the educational goal. Therefore, the teacher's educational concept should be changed to pay more attention to cultivate students' active participation and creation. Thus, students' capability of self study and information collection will be improved with the powerful support of network information technology.

Informatization education based on network will not be restricted by time or space so that students will have more diversified channels to knowledge acquisition. Besides traditional environment of class teaching, students can also browse mass information on the Internet by their interests, which can improve their capability of independent study as well as their ability of knowledge selection indirectly. Moreover, with the advanced search engine technology such as Google and Baidu, students can acquire information conveniently and fast since they only type in the keywords for what they need.

The effect on teaching method. The development of network information technology has familiarized people with this emerging educational means and educational carrier. Under the background of information technology, teaching method has been developed in all dimensions without being restricted to traditional class teaching with blackboard and chalks only; instead, it has made better use of multi-media and computer technology by taking them as auxiliary teaching means. The carrier of network information technology has provided students with a freer and more flexible learning space so that students can better understand and perceive knowledge by videos, pictures, 
animations and music. Such kind of teaching method is more colorful and original, which can greatly promote the teaching efficiency.

The effect on educational system and educational concepts. The online informatization education not only possesses large amount of information resources, but it is not restricted to time or space, which has made educational system more diversified to some extent. Apart from traditional school education, remote education has also become an emerging educational strength with bigger and bigger effect. Meanwhile, more and more people have benefited from the convenient learning means, and thus the concepts of lifelong education as well as socialized and individualized education have also deep inside people's mind, which provides powerful material and technical guarantee for the coordination and cooperation of family education, social education and school education. At the same, it offers powerful support for the formation of an overall and all-round-way educational concept and educational system.

\section{The significance of a new carrier for music education under network era}

In the past 100 years from the end of 19th century to the end of the 20th century, human beings had experienced a historical period with the most rapid development of high technologies, and by far, scientific and technological level has reached an unprecedented new high. At the same time, educational carrier has also been innovated with the revolution of science and technology. A series of educational carriers based on electrical technology such as camera, wireless equipment, television, recorder and projector and so on have been created consecutively, which has greatly changed teaching methods.

These newly emerged educational carriers have created a new situation for education. More and more people began to acquire knowledge on the Internet. Thus, network has become an emerging educational means which produces positive significance for the conversion of educational ideas and opinions; and meanwhile the educational efficiency has also been improved a lot. These newly emerged educational carriers have become major teaching strength. Innovation of music education carrier has profound significance for music education, which are combined together closely.

The scientific and technological innovation has also brought innovation for educational carrier. The effects and significance of new music education carrier on music education are manifested in the following aspects.

The traditional teaching mode has been changed and limitations by time and space have been broken through, which creates a new era of remote education. The remote education has very obvious advantages for its mass online information and convenient usage, which has become an organic part of contemporary teaching. At present, college of remote education has been established widely in colleges and universities so that more people can acquire knowledge by this new educational means. Since such teaching mode is not restricted by time or space with large users, educational institutes in many countries have established professional education websites consecutively. This modern remote education has integrated with various advanced technical means such as video, audio and text so as to stimulate an all-round-way teaching environment to reach the teaching goal.

The innovation of music education carrier has led to diversified students' learning methods and means of knowledge acquisition with better development. If students can't master knowledge they learn in class well, they can record the contents by some recorders so that they can better understand them with better learning efficiency. For example, not all students in performance major such as 
instrument or vocal music can find a feeling during their study process or perceive the performance that teacher said. In this way, students can have a better understanding by recording the contents in class, which is beneficial for their music study. With the multi-media and computer technology, music learners can accept music education easily by multi-media technologies such as DVD player or network videos by famous teachers without being limited to time or space. Therefore, innovation of education carrier can help students to make better and rational use of teaching resources.

The innovation of music education carrier is important for the extensive popularization of national music education and improvement of national music qualities on the whole. All of the world has been covered with Internet, in which various professional or non-professional institutes home and abroad have set particular music channels with colorful contents, such as classes by masters, interviews of musicians, lectures of music educationists and concerts of performers and so on. This carrier has wide and massive users, which can increase people's interest in music study so that audience can have better and deep understanding of music. It's really an important carrier for the popularization of national music education.

Thanks to the achievements of information technology, development of education carrier has experienced an electrical and networking development, which undertakes major tasks of realizing educational resources sharing with its particular and increasingly obvious advantages. Various education websites, as huge resource platforms, have promoted the diversified development of education. Music education website, as a whole new education carrier, has integrated with large amounts of information technology. It indicates the innovative significance of educational means and educational materials.

\section{Music education and music education website}

Since the 21 st century, the carrier for music education has experienced an unprecedentedly comprehensive and fast development. At present, the concept of music education covers a wide range including school music education and social music education. In general, school education can be divided into pre-school education, primary education, higher education and adult education, etc. School music education can also be divided into professional music education and common music education. As for common music education, it means music education among students in compulsory educational periods, pre-school as well as non-professional colleges or universities. However, professional music education mainly takes the cultivation of various professional talents as its goal. There is still another kind called normal music education, which aims to cultivate music teachers at all levels. Meanwhile, social music education is also an important part of music education, including community art center, youth palace, amateur music training school as well as universities for the aged, etc. In this paper, study on music education websites is mainly based on school music education.

Organizations and institutes for music education as well as professional colleges and universities home and abroad have all established their own exclusive music education websites, which is of especially important significance for both educators and educatees. They advocate their own characteristics and concepts of music education by means of websites so that learners can select the sources and contents of knowledge freely by comparison. This convenient learning method has become one of the most important means for acquiring knowledge about music education. Music education website is now a form which can embody music educational thoughts comprehensively to some degree. 
Websites for music education is just a branch of educational websites, so we need to make clear about educational websites first. Educational website is the main form of network educational resources. It is an educational platform or database of teaching resources established by collecting, processing and storing educational resources, and meanwhile it provides tools for information acquisition and searching. Besides, online users are also provided with service related to teaching and other educational information. Likewise, website for music education is mainly responsible for conducting music teaching by various advanced information technologies such as texts, videos, audios and animations so as to present music education contents comprehensively.

From the angle of technical means, music education website, as an emerging educational form, has many features such as digitization and networking, within which the most important feature is that it can present network resources about information and education comprehensively. Professor Cheng Huanwen from Sun Yat-sen University has defined network information resources as follows. According to him, "network information resources are information resources which store texts, pictures, voices and animations in the form of electronic data in non-paper carriers like disks and tapes, and then the resources will be presented by network and computer." Networking education resources are major parts of information resources, and education website is right the most important non-paper carrier. Website for music education, as an emerging education carrier has integrated various factors of network information technology.

\section{The effects of website on music education mode and behavioral mode}

Innovation of teaching mode. Music education with website as its main carrier has gradually become a major part of human's activities for music education, which has an unprecedented effect and significance for contemporary music education. The greatest advantage of network education is that it won't be restricted by time and space, which has created a whole new era for the conversion of information communication. A simulated teaching environment is made by network education to reach the teaching goal, and it has become an organic part of contemporary teaching. At present, online courses have been established by various conservatories of music, especially the Central Conservatory of Music and Shanghai Conservatory of Music which contributed a lot to online education. Meanwhile, excellent courses taught by experts or professors are selected as the core contents of their school network educational system, which greatly promoted the quality and level of their network education.

Network education has provided students with wide access to resources, for example, students can gain mass information by clicking Digital Library of Columbia University and typing the keywords. Meanwhile, video lessons by musicians home and abroad can also be obtained without being restricted by time and space, which can seen as an auxiliary form of music education for traditional mode. Music education has become diversified due to networking technology. It overcomes the limitations of traditional teaching mode so that people can have access to large amount of related knowledge at home conveniently.

The cultural trend of a diversified educational concept. In today's society of global integration and pluralistic culture, it is of enlightening significance for the revolution of Chinese music educational system to study pluralistic music education and world music education. The so-called pluralistic culture means the common development of multiple cultures. For a long time, our human society has always been deeply affected by multiple cultures such as ancient Greek culture, traditional Chinese culture and African culture and so on. Under the global vision of pluralistic 
culture, various nationalities all around the world are having cross-cultural communications frequently. Therefore, study on ethnic music in different countries and peoples also has an important role in expanding music education; however, music education website is undoubtedly a best platform.

Music education website plays an important role in protecting intangible cultural heritages. With the rapid development of global integration, local ethnic culture and ecology of many countries have suffered unprecedented resistance. Intangible cultural heritages have been impacted a lot with an increasing disappearance of cultural heritages inherited by words and behaviors. Meanwhile, our survival environment has also deteriorated greatly. Therefore, protection and inheritance of ethnic music culture are faced with serious situation. Under this circumstance, various music education websites can upload these valuable resources on the Internet by advanced information technology to promote and advocate them so that more people can have an access to these materials.

Music education website is helpful for the establishment and study of music learning mode. At present, the traditional teaching mode of oral and mental instruction is not quite suitable for online music education, which has high demand for networking technology communication with a lack of popularity. As for the study of musical theories, there may be greater potentials and values. There have been many theoretical contents, from policy formulation to specific items like curriculum setting, teaching plans and teaching schemes, so we need to make further study on building a balanced relationship between networking theories and music education.

\section{Limitations and proposals to contemporary networking music education}

Compared to traditional music teaching mode, networking music education has many obvious advantages such as no limitation to space or time, mass information and flexible and independent teaching mode, etc. However, network education is just an auxiliary teaching strength instead of dominant teaching strength. A teaching mode breaking through time and space is surely with many defects. Therefore, some proposals and countermeasures will be discussed in the following parts.

Limitations on technical level. From descriptions of music education websites above, we find that educational resources on various music education websites home and abroad are mainly presented in five ways, which are texts, videos, pictures and networking search engine, and all of them belong to the range of information technology. With advanced configuration of multi-media computer technologies such as central processing unit, audio card, graphic accelerator and network interface as well as access to Internet, all the educational resources can be presented in a vertical way, and such comprehensively vertical effect is incomparable by other educational technologies.

Limitations to the teaching methods of knowledge. Networking education plays an extremely important role in theoretical courses of music education. With the technology of search engine, mass music knowledge from ancient times to today such as Chinese and Western music history, composing styles of Chinese and Western composers and so on can be found easily and presented in the form of pictures, texts, sounds and images so as to deepening the understanding of knowledge. Besides, excellent courseware, teaching schemes and video lessons by experts and professors can be downloaded on music education website. All of this can create a virtual teaching environment for people's theoretical study.

Uneven qualities of music educational resources. Network is an extremely free space where people can upload, download and browse various music educational resources freely, and thus network has become a platform with mass resources objectively. Click rates of various music 
education websites have increased gradually with larger influence as well. However, due to the lack of effective management mechanism, standard of academic papers is seriously unbalanced. Educational websites are filled with academic papers of poor quality, which brings inconvenience for people's study. What's worse, this has created a bad social circumstance, for example, the same paper may be shown in many different websites in different people's names.

According to analysis above, we can conclude that although music education based on network may have much inefficiency, these defects can be improved and perfected by a series of means. First, technical problems can be researched and solved with high-tech means by professionals. It's merely an issue of time. If these technical difficulties are solved, music education based on website can be applied to teaching successfully. Another problem is about teaching mode. Network music education based on digital technology can be used to complement education of music skills as an important auxiliary strength, which is of stronger scientificity compared to traditional teaching of skills.

\section{Conclusions}

Human's civilization and history, characters and printing technology are all all landmarks during the development of educational carriers, which have also brought leaps for educational materials, educational system and educational mode. Since the 21 st century, network information technology has been developed rapidly with Internet as its symbol. Internet has not only become a channel for human's communication, but it also becomes one of the most effective means for knowledge acquisition. In particular, Internet plays an important role in the promotion of remote education, pluralistic education, lifelong education and individualized education. Information on the Internet is massive with constant improvement. The author has just got the news that a World Digital Library has been officially established by UNESCO. Seven languages will be adopted for the digital library and it has collected excellent intellectual and spiritual heritages of the past thousand years, including valuable scripts of different nations in different historical periods, literature documents, arts as well as music cultural heritages and so on, within which there are mass pictures, texts and video resources can be offered for users' references. This is another best source for acquiring excellent music educational resources. A huge resources library built jointly by UNESCO and major libraries all over the world is really an innovative practice. In this sense, resources on the Internet are really of powerful and surprising potentials.

As an emerging education carrier, network has certain defects together with some advantages. It is responsibilities of each music educationist to better use these advantages to develop music education career and overcome these limitations.

\section{Acknowledgment}

A major subject of artistic planning in Jiangxi province. Integration and Development of Work Song During Cultural Construction in New Villages in Jiangxi Province. Serial No. YG201405

\section{References}

[1]Bennett Reimer, Philosophy of Music Education. People's Music Publishing House, 2003.Caoli, Music Education Under Subject Pedagogy. 2000.

[2]Caoli, Outline of Common Music Education. Press of Beijing Normal University. 1990. 
[3]Cheng Huanwen, Pan Yantao. Information Resources Sharing. Higher Education Publishing House. 2004.

[4]Dong Hongbin, Modern Educational and Technological Courses. China WaterPower Press. 2005.

[5]Dong Yuqi, Comparative Study on International Information Technology Education. People's Education Press. 2005.

[6]Dana, Philosophy of Art. Press of Tianjin Academy of Social Science. 2004.

[7]Guan Jianhua, Chinese Music Education and World Music Education at the Turn of the Century. Press of Nanjing Normal University. 2002.

[8]Gu Mingyuan, Xuan Liyin, Education and National Development with Introduction to Comparative Education. People's Education Press. 1996.

[9]Guo Shengjian, Theories of Music Education. Hunan Literature and Art Press. 2004. 